Beckman, H. (1961). Pharmacology: The Nature, Action and Use of Drugs, 2nd ed. p. 487. Saunders, Philadelphia.

Boxer, L., Anderson, F. P., and Rowe, D. S. (1969). Comparison of ipecac-induced emesis with gastric lavage in the treatment of acute salicylate ingestion. Fournal of Pediatrics, 74, 800.

Burke, M. (1969). Hospital treatment of acute poisoning. Lancet, $1,306$.

Deichmann, W. B., and Gerarde, H. W. (1964). Symptomatology and Therapy of Toxicological Emergencies. Academic Press, New York.

Gosselin, R. E., and Smith, R. P. (1966). Trends in the therapy of acute poisonings. Clinical Pharmacology and Therapeutics, 7, 279.

Shirkey, H. C. (1966). Ipecac syrup. Its use as an emetic in poison control. Fournal of Pediatrics, 69, 139.

\section{Transient Gluten Intolerance Sir,}

I have read with interest the Case Report by Dr. Walker-Smith in your previous issue (p. 523), which describes a patient with presumed transient gluten intolerance. The author has argued his case closely and correctly makes it clear that the patient does not suffer from coeliac disease which, by definition, means permanent gluten intolerance. However the evidence for transient intolerance rests solely on the child's clinical improvement coincident with the removal of gluten from the diet. It seems to me that an alternative explanation could be considered. It is noted that just before the institution of a gluten-free diet the child's serum proteins were returned to a more normal level. Might this not have stimulated growth recommencement, as it may do in a condition such as kwashiorkor? Could perhaps this patient have been one who originally suffered a gastroenteric type of illness which resulted in prolonged small intestinal mucosal abnormality, a recognized phenomenon? This may have been associated with protein leak and the child had protein-losing enteropathy which eventually resolved as the mucosa healed.

On the other hand, Dr. Walker-Smith's explanation may be the correct one. However, my purpose in writing is to point out that, though in experienced and critical hands the diagnosis of transient gluten intolerance means that follow-up and retesting will be carried out, if this diagnosis is used freely by those less experienced there well may be more patients who are treated with a gluten-free diet and are uncertain how long the diet is to be continued. Those of us who are involved in investigating paediatric patients with gastro-enterological problems have many such patients referred to us with the query, does this patient really suffer from coeliac disease and how long should he be on a glutenfree diet? As I have said, present evidence indicates that the 'true coeliac' should remain on a gluten-free diet for life. When retesting the validity of a previous diagnosis of coeliac disease or wheat gluten intolerance, there is no diagnostic evidence available while the patient is on a gluten-free diet and, as Dr. Walker-Smith points out, relapse on resuming consumption of glutencontaining foods may be slow and retesting may have to be carried out periodically over several years. This is naturally very arduous for both patient and doctor. Hence accurate initial diagnosis is important.

Before a diagnosis of transient gluten intolerance is contemplated I feel that all other explanations for the patient's symptoms and signs should be carefully contemplated. If one does decide to exclude gluten, then careful follow-up is certainly mandatory.

Charlotte M. ANDERSON

Institute of Child Health,

The Nuffield Building,

Francis Road,

Birmingham 16.

Attention may be drawn to the observation of McNeish in this journal $(1968,43,362)$ that if in true coeliac disease gluten is reintroduced into the diet, not more than 2 months is needed before the jejunal biopsy pattern becomes clearly abnormal. This could be relevant to the problem mentioned by Professor Anderson, of deciding whether a gluten-free diet should be continued in cases where the validity of the original diagnosis of coeliac disease has been questionable.-Editor. 